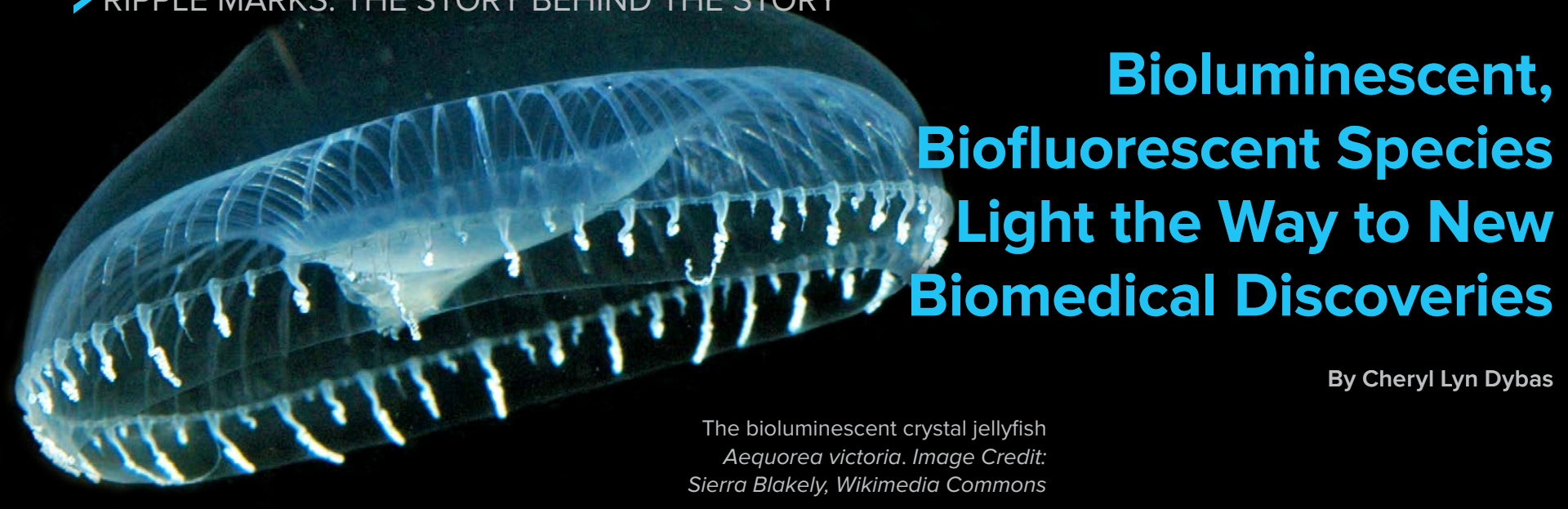

Throughout history, humans have been fascinated with the "living light" produced by luminescent organisms. Today, the glimmering power of bioluminescence has been harnessed for lifesaving uses in medicine, from lighting up structures inside the brain to illuminating the progression of cancer cells.

One of the first accounts of bioluminescence and health was written in $77 \mathrm{CE}$. In Historia Naturalis, Roman physician and naturalist Pliny the Elder described medicinal substances derived from aquatic animals, including pulmo marinus. A jellyfish now known as Pelagia noctiluca, Latin for "night light of the sea," the species emits a glowing substance from the outer edge of its bell. When boiled in water or taken in wine, Pliny believed, pulmo marinus treated "the gravell and the stone."

Also in the first century, Greek physician and botanist Pedanius Dioscorides posited in De Materia Medica, an herbal medicine encyclopedia he penned, that "pulmo marinus being beaten small whilst it is new and so applied, doth help such as are troubled with chillblanes and such as ye have goute."

Some two thousand years have passed since the time of Pliny and Dioscorides. Only recently, however, have researchers discovered exactly how bioluminescence is created, let alone how to employ it in cures for disease.

The sparkle of marine bioluminescence occurs in species from fish in the deep ocean to jellyfish and dinoflagellates in the shallows, among others. They create light through the interaction of the enzymes luciferase and luciferin (the terms are derived from the Latin word lucifer-lightbringer), or by hosting light-emitting bacteria. Biofluorescence, sometimes confused with bioluminescence, is released when an animal such as a jellyfish or eel absorbs light and re-emits it in a different color.

Now, "a vast range of analytical techniques has been developed based on bioluminescence," write Zinaida Kaskova, Aleksandra Tsarkova, and Ilia Yampolsky of the Russian Academy of Sciences and the Pirogov Russian National Research Medical University in a 2016 paper in Chemical Society Reviews.

"Immunoassays, gene expression assays, drug screening, bioimaging of live organisms, cancer studies, and the investigation of infectious diseases," the scientists state, are just the beginning of a tale of 1,001 lights, as the researchers refer to the growing number of bioluminescence discoveries with applications in medicine.

\section{A REVOLUTION IN SCIENCE}

An early chapter in the tale of 1,001 lights, according to neurobiologist Vincent Pieribone, director of the John B. Pierce Laboratory at the Yale University School of Medicine, is green fluorescent protein (GFP). GFP is found in the crystal jellyfish Aequorea victoria. This and other fluorescent proteins have revolutionized research in fields from immunology to neuroscience.

Many organisms are now known to manufacture fluorescent proteins. "These proteins are extending the boundaries of science, including allowing researchers to understand, manipulate, and interact with the living brain," says Pieribone.

When scientists develop methods that allow them to see things that were once invisible, research takes a giant

Image of the bioluminescence of Chaetopterus, the parchment tubeworm. Image credit: David Liittschwager, Scripps Institution of Oceanography leap forward. For example, in the seventeenth century, Anton van Leeuwenhoek invented the microscope. A new world opened. Scientists could suddenly observe previously unknown bacteria and blood cells. So it is with fluorescent proteins, Pieribone says.

\section{BRIGHT GREEN EEL PATENT}

Based on a bright green fluorescent protein found in two fish-the false moray eels Kaupichthys hyoproroides and Kaupichthys n. sp.-Pieribone's team was awarded a patent for a new method of detecting bilirubin in blood or urine. Bilirubin is produced in bone marrow cells and in the liver as the end product of red blood cell (hemoglobin) breakdown.

High levels of bilirubin may indicate liver damage or other disease. Molecular Tools LLC, a biotech company in Frederick, Maryland, is working with the scientists to develop new ways of testing for bilirubin based on these proteins.

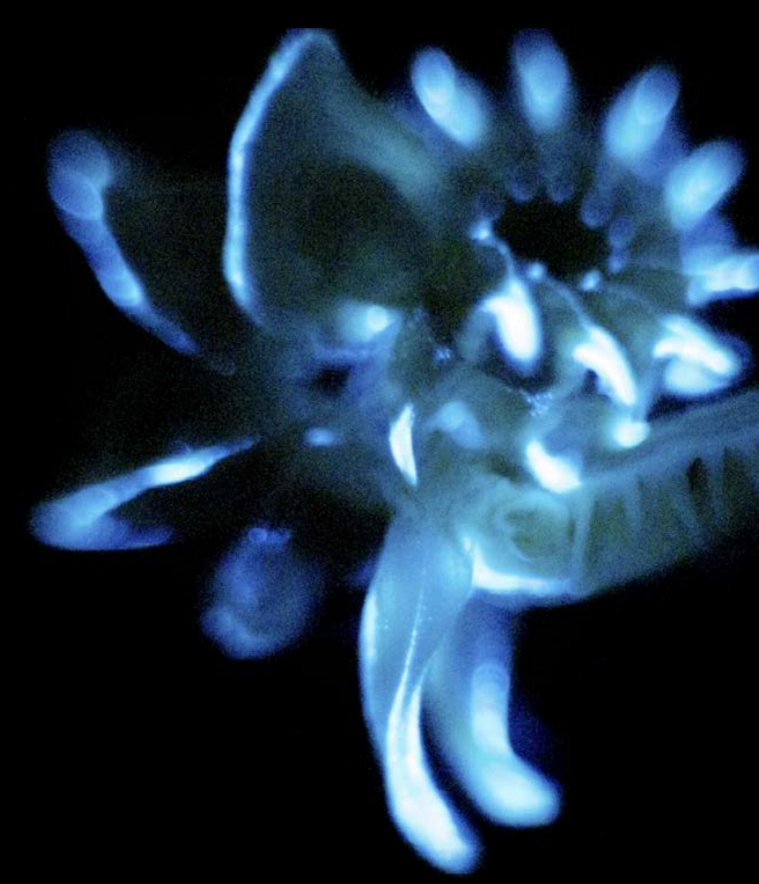


